\title{
Seismology inside the Fault Zone: Applications to Fault-Zone Properties and Rupture Dynamics
}

\author{
by William L. Ellsworth, Peter E. Malin, Kazutoshi Imanishi, Steven W. Roecker, \\ Robert Nadeau, Volker Oye, Clifford H. Thurber, Felix Waldhauser, \\ Namoi L. Boness, Stephen H. Hickman, and Mark D. Zoback
} doi:10.2204/iodp.sd.s01.04.2007

A central goal of seismology is to understand the physics of earthquakes and other sources of seismic waves in the Earth. We would like to understand how dynamic instabilities are nucleated, how they evolve in space and time, and how they come to rest. To achieve this goal, we need observations that are truly broadband with respect to source process time scales. Because the high-frequencylimit of a seismogram directly controls the spatial scale at which we can resolve these processes, the requirement for "broadband" means bandwidth that is sufficient to record the shortest pulse produced by the physical system (a delta function being the ultimate broadband signal). Although there is considerable uncertainty at present about the upper frequency limit needed to capture dynamic processes, it is clearly well above the frequency range of standard seismological instrumentation (typically $30-40 \mathrm{~Hz}$ for 100 sample-per-second data). Even when instruments are capable of observing frequencies above $1 \mathrm{KHz}$, they must be sited close enough to the source to overcome the attenuation of the high frequency waves due to scattering and anelastic loss during propagation from the source. The natural solution to this problem is to emplace the instrumentation within the near-field of the source in boreholes and deep mines. This paper presents a review of some recent results from three deep $(>2 \mathrm{~km})$ boreholes in California. The three boreholes considered are the Long Valley Exploratory Well, the San Andreas Fault Observatory at Depth (SAFOD) Pilot Hole, and the SAFOD Main Hole.

The Long Valley Exploratory Well (LVEW) is a $3.0-\mathrm{km}$ deep research drill hole located near the center of Long Valley caldera in eastern California. The well was drilled in a series of stages beginning in 1989, and completed to a total depth of $2996 \mathrm{~m}$ in 1998 (Sackett et al., 1999) as part of the International Continental Drilling Program (ICDP) Long Valley Coring Project. Prior to the final stage of drilling, a 3-component $10-\mathrm{Hz}$ seismometer, installed at a depth of $2050 \mathrm{~m}$ from September 1997 through May 1998, recorded tens of thousands of local events during the 1997-1998 seismic crisis in Long Valley Caldera (Prejean and Ellsworth, 2001). The value of recording at depth is clearly evident in the comparison of near-source recordings made at the surface and deep underground (Fig. 1).

In the fall of 2002, the well was converted into a deep geophysical observatory which now has a 3-component $4.5-\mathrm{Hz}$ seismometer installed at a depth of $2600 \mathrm{~m}$. Earthquakes as small as M2.5 have been observed at distances as close as $300 \mathrm{~m}$ from the seismometer (Fig. 2). Currently, the data sample rate is limited to $500 \mathrm{sps}$, which limits the highest resolvable frequency to $200 \mathrm{~Hz}$. All data are available through the Northern California Earthquake Data Center (http://www.ncedc.org/). While this sample rate is adequate to detect even such small events, it is not adequate to resolve the event corner frequency. Increasing the sample rate alone, however, will not guarantee that source processes can be measured. The attenuation of seismic waves, even over distances of hundreds of meters, presents a formidable challenge to the modeler. The tradeoff between earthquake source parameters and attenuation makes it difficult to separate path effects from source effects. Ide et al. (2003) overcame this problem by employing a spectral ratio method to re-interpret some of the earthquakes analyzed earlier by Prejean and Ellsworth (2001). The reanalysis demonstrated how propagation effects can contaminate source parameters interpreted from individual event recordings, even in the high frequency environment of the deep borehole.

The importance of wave attenuation and scattering even in the high $\mathrm{Q}$ environment of a deep borehole was further reinforced by seismic data collected by the 32-level, 1240- mlong array installed in the $2.1-\mathrm{km}$ SAFOD Pilot Hole (Chavarria et al., 2004). This vertical borehole was drilled in 2002 as an ICDP project and part of the pre-Earth Scope site

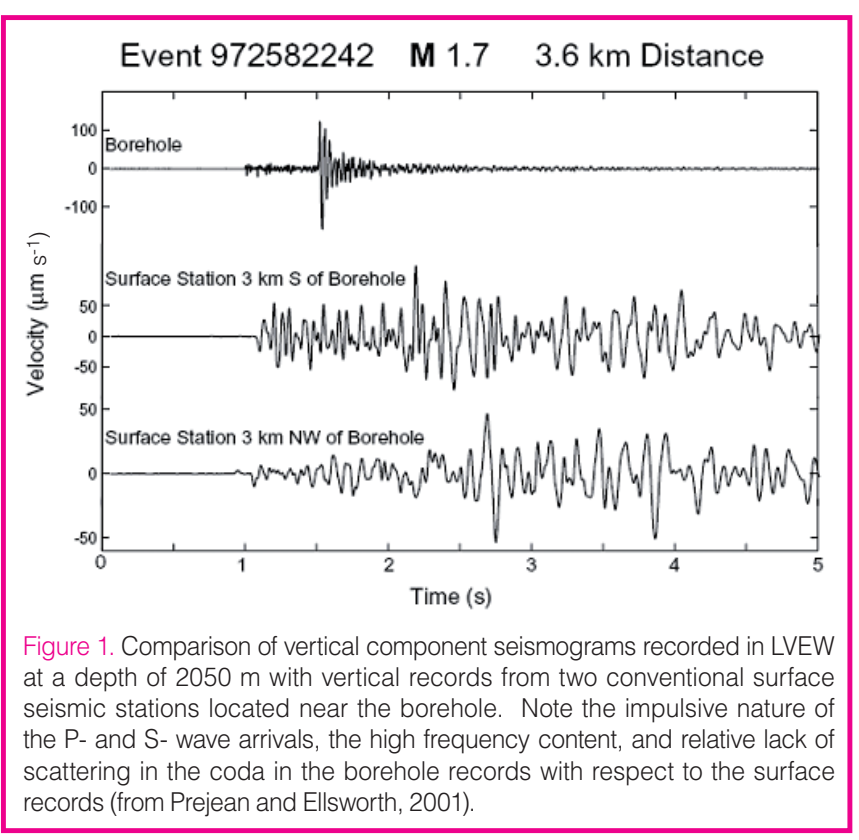




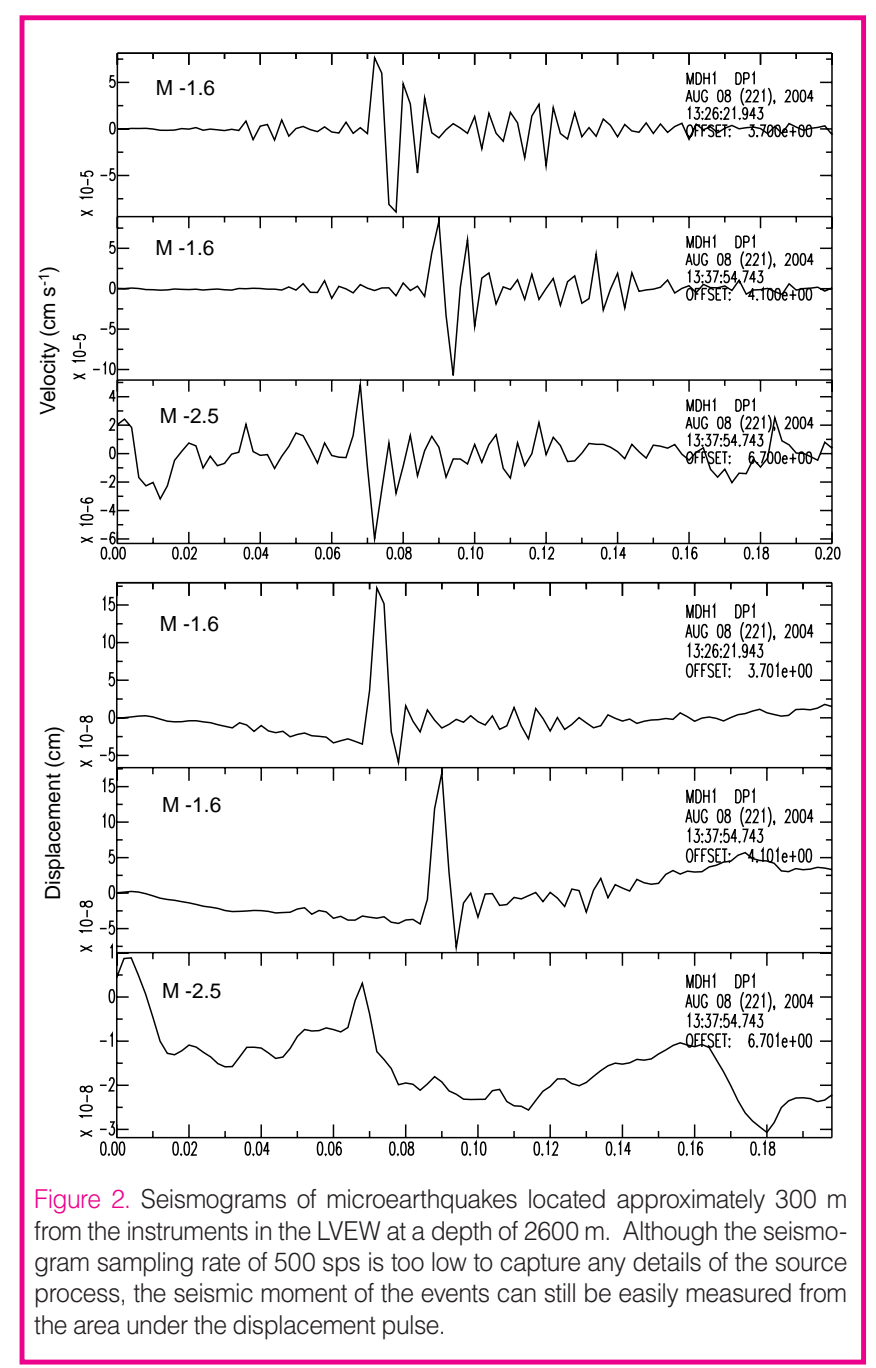

investigation program at SAFOD. Installed in granite between $856 \mathrm{~m}$ and $2096 \mathrm{~m}$ below ground level, the array recorded at sample rates between 500 sps and 1000 sps from September 2002 to April 2005. All data are available through the Northern California Earthquake Data Center. The effects of propagation on the seismograms are clearly evident in Fig. 3, which shows the seismograms of a microearthquake

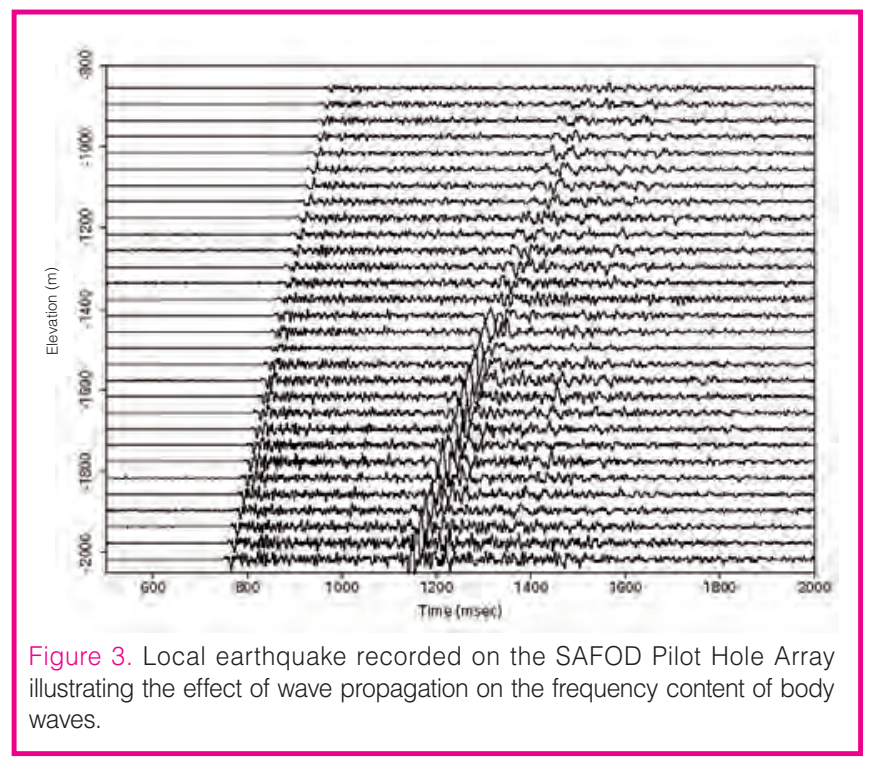

located about $2.5 \mathrm{~km}$ from the array. Note the loss of high frequency content as the wave propagates up the borehole.

Imanishi and Ellsworth (2006) applied a multi-window spectral ratio (MWSR) to seismograms of earthquake multiplets recorded in the SAFOD Pilot Hole. This procedure extended the method of Ide et al. (2003) by stacking multiple time windows of the direct body wave and its early coda to suppress noise and improve the recovery of the spectral ratio (Fig. 4). Results of their study indicated that there is no scaledependence to static stress drop or apparent stress for earthquakes on the San Andreas Fault between M0.2 and M2.1.

The SAFOD Main Hole was drilled through the San Andreas Fault to a total vertical depth of $3.1 \mathrm{~km}$ in 2005. It provides a portal into the inner workings of a major plate boundary fault that makes it possible to conduct spatially extensive and long-duration observations of active tectonic processes within the actively deforming core of the San Andreas Fault.

To meet the scientific and technical challenges of building the observatory, boreholeinstrumentation systems developed for use in the petroleum industry and by the academic community in other deep research boreholes have been deployed in the SAFOD pilot hole and main hole over the past three years. These systems included $15-\mathrm{Hz}$ omni-directional and $4.5-\mathrm{Hz}$ gimbaled seismometers, micro-electromechanical accelerometers, tiltmeters, sigma-delta digitizers, and a fiber optic interferometric strainmeter. A 1200-m-long, 3-component 80-level clamped seismic array was also operated in the main hole for 2 weeks of recording in May of 2005, collecting continuous seismic data at 4000 sps.

Some of the observational highlights included capturing one of the SAFOD target repeating earthquakes in the near-field ata distance of $420 \mathrm{~m}$, with accelerations of up to $200 \mathrm{~cm} \mathrm{~s}^{-1}$ and a static displacement of a few microns (Fig. 5). Numerous other local events were observed over the summer by the tilt and seismic instruments in the pilot hole, some of which produced

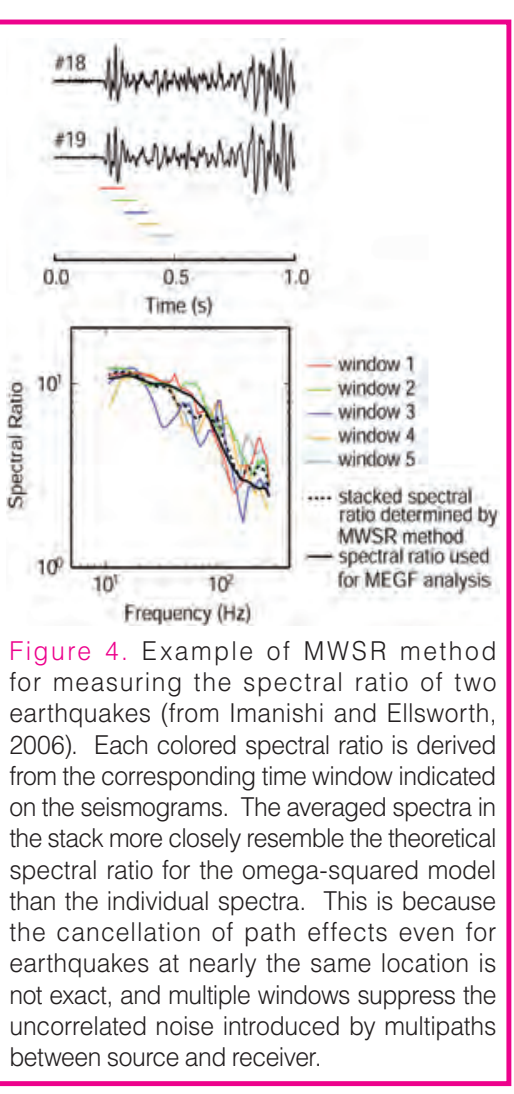


strain offsets of several nanostrain on the fiber optic strainmeter.

An exciting discovery made in the SAFOD Main Hole was a new type of seismic wave: a fault zone guided P-wave (Fig. 6). This phase arrives between the $\mathrm{P}$ - and $\mathrm{S}$-waves, is normally dispersed, and has a clear Airy phase. It was recorded by $15-\mathrm{Hz}$ seismometers located $2650 \mathrm{~m}$ below ground, $3270 \mathrm{~m}$ along the inclined borehole, and approximately $40 \mathrm{~m}$ from the center of a major fault that the borehole crossed. This fault has caused deformation of the borehole casing, indicating that it is one of the active stands of the San Andreas system. The existence of this phase depends on unique relationships between the $\mathrm{P}$ and $\mathrm{S}$ velocities of the fault and surrounding rocks, as well as their thicknesses. Its propagation speed, low frequency cut-off, and Airy phase frequency thus give special insights into the structure and multistranding of the San Andreas Fault zone.

In summary, observations of earthquakes at very short distances in the three borehole observatories in California demonstrate the many advantages of observing earthquake processes at short distances in deep wells. Near-source recordings are essential for the study of earthquake source processes, particularly the nucleation and early growth of dynamic rupture. SAFOD data will continue to provide a benchmark for theoretical and numerical models of earth-

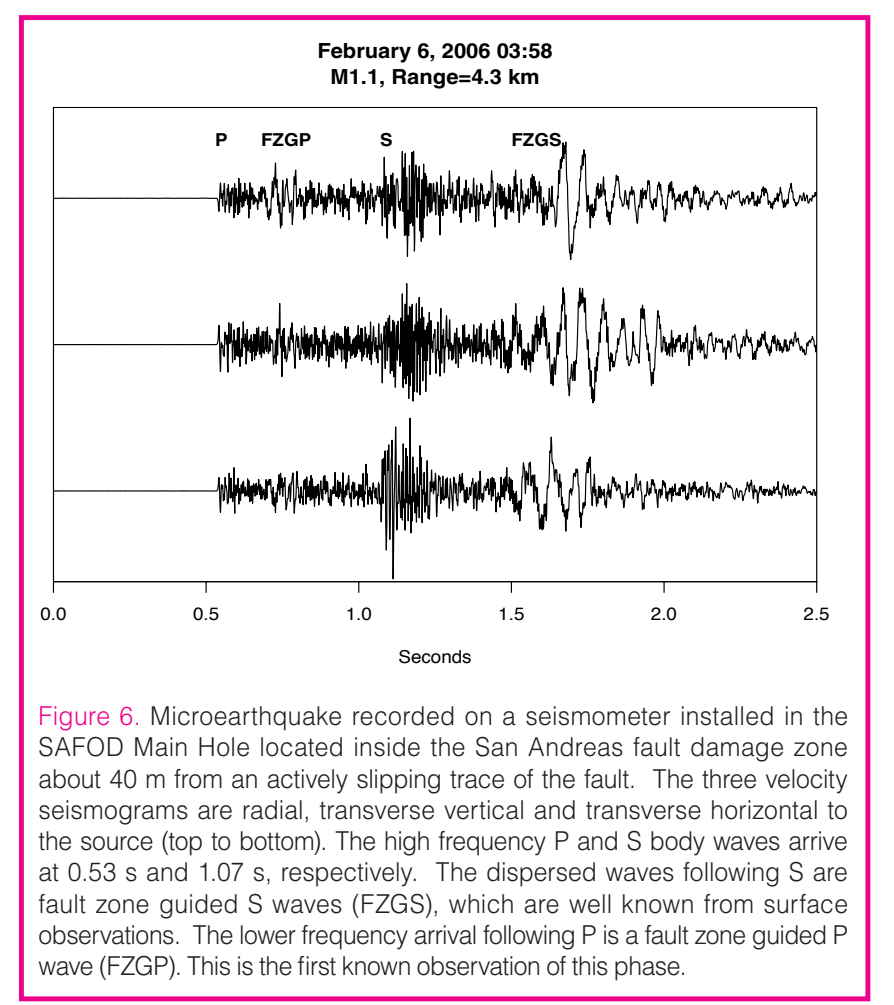

quake processes and laboratory rock experiments, and complementary data to near-source observations of large magnitude earthquakes. Numerical simulations of the earth-
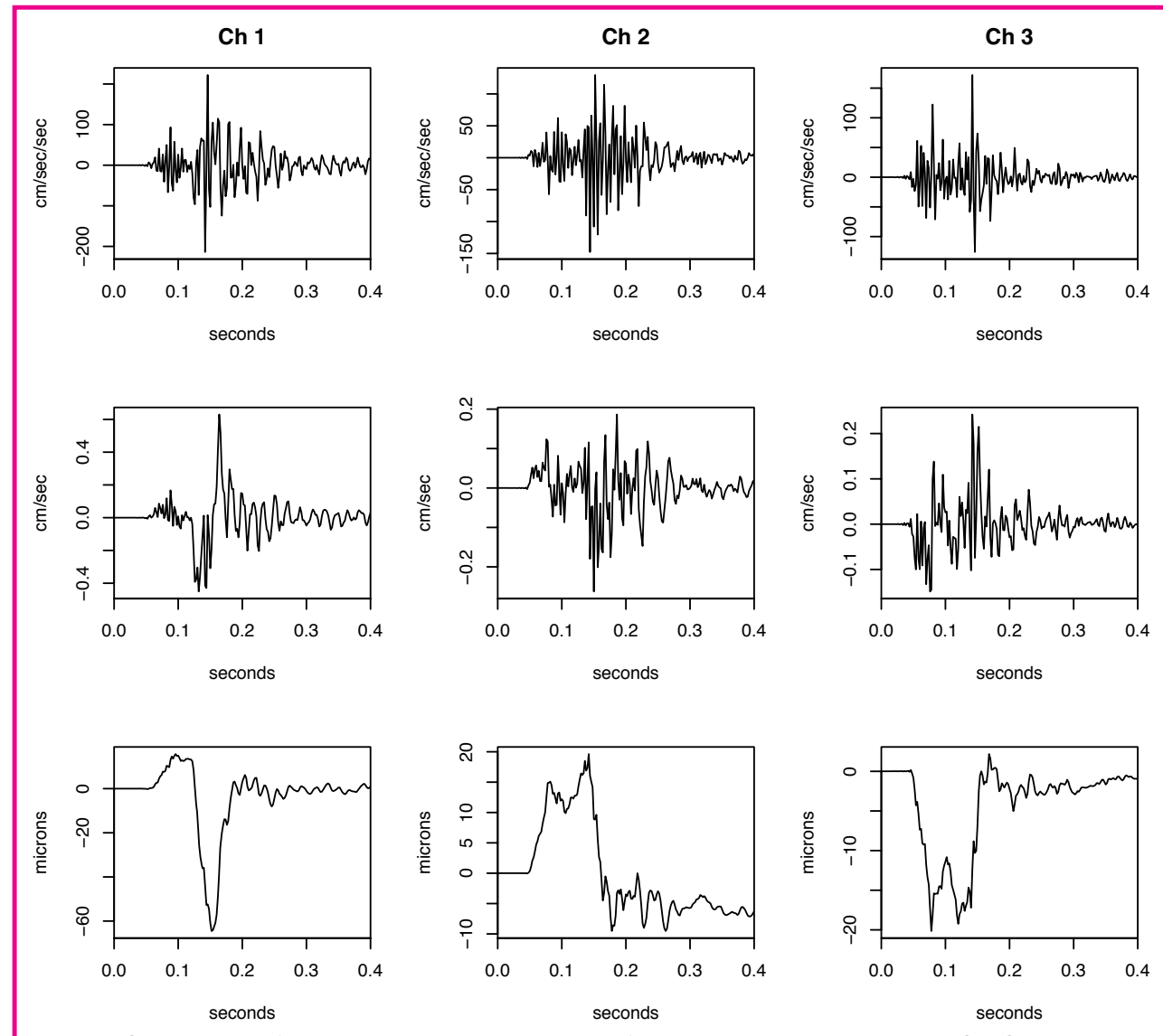

Figure 5. Seismograms of the M1.9 "L.A." target earthquake of 23 January 2003 recorded in the SAFOD Main Hole by a micro-machined accelerometer (Colibrys SF-1500). The original accelerograms (top row) were integrated to velocity (middle row) and displacement (without filtering). At this distance, the near-field contributions to the displacement seismogram become important and are clearly evident in these records. quake on rate-and-state faults have now advanced to the point that they can produce numerically accurate models that span the slow earthquake loading cycle and dynamic rupture on fault patches of comparable dimension to the SAFOD target earthquakes. We should anticipate a productive interchange between observations, theories, models and laboratory experiments, as we begin to gather data in the near field of the target earthquakes.

\section{References}

Chavarria, A., Malin, P.E., and Shalev, E., 2004. The SAFOD Pilot Hole seismic array: Wave propagation effects as a function of sensor depth and source location. Geophys. Res. Lett., 31:L12S07, doi:10.1029/ 2003GL019382.

Ellsworth, W.L. and Malin, P.E., 2006. A first observation of fault guided PSV-waves at SAFOD with implications for fault character- 
istics. EOS Trans. Am. Geophys. U. 87(52): Abstract T23E02 .

Ide, S., Beroza, G.C., Prejean, S.G., and Ellsworth, W.L., 2003. Apparent break in earthquake scaling due to path and site effects on deep borehole recordings. J. Geophys. Res., 108(B5), 2271, doi:10.1029/2001JB001617.

Imanishi, K., and Ellsworth, W.L., 2006. Source scaling relationships of microearthquakes at Parkfield, CA, determined using the SAFOD pilot hole array. In Abercrombie, R.E., McGarr, A., Di Toro, G., and Kanamori, H. (Eds.), Earthquakes: Radiated Energy and the Physics of Faulting, Geophys. Monogr. 170, Washington D.C. (American. Geophysical Union), 81-80.

Prejean, S.G. and Ellsworth, W.L., 2001. Observations of earthquake source parameters at $2 \mathrm{~km}$ depth in Long Valley Caldera, eastern California. Bull. Seismolog. Soc. Am., 91: 165-177, doi:10.1785/0120000079.

Sackett, P.C., McConnell, V.S., Roach, A.L., Priest, S.S., and Sass, J. H., 1999. Long Valley Coring Project, 1998 - Preliminary Stratigraphy and Images of Recovered Core. U.S. Geological Survey Open-File Report 99-158.

\section{Authors}

William L. Ellsworth, 3A-109, U.S. Geological Survey (USGS), 345 Middlefield Road Mail Stop 977, Menlo Park, Calif. 94025, U.S.A., e-mail: ellsworth@usgs.gov

Peter E. Malin, 109A Old Chemistry Box 90227, Duke University, Durham, N.C. 27708, U.S.A., e-mail: malin@ duke.edu

Kazutoshi Imanishi, Geological Survey of Japan, Institute of Geology and Geoinformation (AIST), Tsukuba Central 7, 1-1-1 Higashi, Tsukuba, 305-8567, Japan.

Steven W. Roecker, Department ofEarth and Environmental Sciences, Rensselaer Polytechnic Institute, Science Center 1S06, Troy, N.Y. 12180, U.S.A.

Robert Nadeau, Berkeley Seismological Lab., 207 McCone Hall, University of California Berkeley, Calif. 94720-4760, U.S.A.

Volker Oye, Norwegian Seismic Array (NORSAR), P.O. Box 53, N-2027 Kjeller, Norway.

Clifford H. Thurber, Department of Geology and Geophysics, University of Wisconsin, 1215 West Dayton Street, Madison, Wis. 53706, U.S.A.

Felix Waldhauser, LDEO-Seismology Geology and Tectonophysics, 210 Seismology, 61 Route 9W - P.O. Box 1000, Palisades, N.Y. 10964, U.S.A.

Namoi L. Boness, Chevron, Energy Technology Centers (ETC), San Ramon, Calif. 94583, U.S.A.

Stephen H. Hickman, USGS, 345 Middlefield Road, Menlo Park, Calif. 94025, U.S.A.

Mark D. Zoback, Department of Geophysics, Stanford University, Mitchell Bldg., Stanford, Calif. 94305, U.S.A.

\section{Related Web Link}

http://www.ncedc.org/ 